\title{
Combined strategies for improving expression of Citrobacter amalonaticus phytase in Pichia pastoris
}

Cheng Li ${ }^{1,2}$, Ying Lin ${ }^{1,2}$, Xueyun Zheng ${ }^{1,2}$, Nuo Pang ${ }^{1,2}$, Xihao Liao ${ }^{1,2}$, Xiaoxiao Liu ${ }^{1,2}$, Yuanyuan Huang ${ }^{1,2}$ and Shuli Liang ${ }^{1,2^{*}}$

\begin{abstract}
Background: Phytase is used as an animal feed additive that degrades phytic acid and reduces feeding costs and pollution caused by fecal excretion of phosphorus. Some phytases have been expressed in Pichia pastoris, among which the phytase from Citrobacter amalonaticus CGMCC 1696 had high specific activity (3548 U/mg). Improvement of the phytase expression level will contribute to facilitate its industrial applications.

Methods: To improve the phytase expression, we use modification of $\mathrm{P}_{A O X_{1}}$ and the a-factor signal peptide, increasing the gene copy number, and overexpressing $\mathrm{HACl}^{i}$ to enhance folding and secretion of the protein in the endoplasmic reticulum. The genetic stability and fermentation in 10-L scaled-up fed-batch fermenter was performed to prepare for the industrial production.

Results: The phytase gene from C. amalonaticus CGMCC 1696 was cloned under the control of the AOX1 promoter $\left(\mathrm{P}_{A O X_{1}}\right)$ and expressed in $P$. pastoris. The phytase activity achieved was $414 \mathrm{U} / \mathrm{mL}$. Modifications of $\mathrm{P}_{\text {AOX } 1}$ and the $a$-factor signal peptide increased the phytase yield by 35 and $12 \%$, respectively. Next, on increasing the copy number of the Phy gene to six, the phytase yield was $141 \%$ higher than in the strain containing only a single gene copy. Furthermore, on overexpression of $\mathrm{HACl}^{i}$ ( $i$ indicating induced), a gene encoding Haclp that regulates the unfolded protein response, the phytase yield achieved was $0.75 \mathrm{~g} / \mathrm{L}$ with an activity of $2119 \mathrm{U} / \mathrm{mL}, 412 \%$ higher than for the original strain. The plasmids in this high-phytase expression strain were stable during incubation at $30^{\circ} \mathrm{C}$ in Yeast Extract Peptone Dextrose (YPD) Medium. In a 10-L scaled-up fed-batch fermenter, the phytase yield achieved was $9.58 \mathrm{~g} / \mathrm{L}$ with an activity of $35,032 \mathrm{U} / \mathrm{mL}$.
\end{abstract}

Discussion: The production of a secreted protein will reach its limit at a specific gene copy number where further increases in transcription and translation due to the higher abundance of gene copies will not enhance the secretion process any further. Enhancement of protein folding in the ER can alleviate bottlenecks in the folding and secretion pathways during the overexpression of heterologous proteins in P. pastoris.

Conclusions: Using modification of $\mathrm{P}_{A O X}$ and the $a$-factor signal peptide, increasing the gene copy number, and overexpressing $\mathrm{HACl}^{i}$ to enhance folding and secretion of the protein in the endoplasmic reticulum, we have successfully increased the phytase yield $412 \%$ relative to the original strain. In a 10-L fed-batch fermenter, the phytase yield achieved was $9.58 \mathrm{~g} / \mathrm{L}$ with an activity of $35,032 \mathrm{U} / \mathrm{mL}$. Large-scale production of phytase can be applied towards different biocatalytic and feed additive applications.

\footnotetext{
* Correspondence: shuli@scut.edu.cn

'Guangdong Key Laboratory of Fermentation and Enzyme Engineering,

School of Bioscience and Bioengineering, South China University of

Technology, Guangzhou 510006, P. R. China

${ }^{2}$ Guangdong Research Center of Industrial Enzyme and Green Manufacturing

Technology, School of Bioscience and Bioengineering, South China

University of Technology, Guangzhou 510006, P. R. China
}

(C) 2015 Li et al. Open Access This article is distributed under the terms of the Creative Commons Attribution 4.0 International License (http://creativecommons.org/licenses/by/4.0/), which permits unrestricted use, distribution, and reproduction in any medium, provided you give appropriate credit to the original author(s) and the source, provide a link to the Creative Commons license, and indicate if changes were made. The Creative Commons Public Domain Dedication waiver (http:// creativecommons.org/publicdomain/zero/1.0/) applies to the data made available in this article, unless otherwise stated. 


\section{Background}

Phytases (myo-inositol hexakisphosphate 3- or 6phosphohydrolases; EC 3.1.3.8 or EC 3.1.3.26) are phosphatases that catalyze the stepwise removal of phosphate from phytate. The addition of phytase to feed for monogastric animals increases phosphorus availability [1], reducing feeding costs by reducing the requirement for supplementation with inorganic phosphorus [2] and the pollution caused by fecal excretion of phosphorus [3]. Most phytases are produced in fungi and bacteria, but only some of them can be expressed at a high level, such as with the Escherichia coli phytase gene appA expressed in Pichia pastoris (118 to $204 \mathrm{U} / \mathrm{ml}$ at the flask scale) [4], Aspergillus niger phytase in A. niger (1008 U/g in flasks) [5], and Citrobacter amalonaticus CGMCC 1696 phytase (420 U/mL in flasks) expressed in P. pastoris [6]. Among these, the phytase from C. amalonaticus CGMCC 1696 has the highest specific activity, $3548 \mathrm{U} / \mathrm{mg}$ [6]. The C. amalonaticus phytase expressed by $P$. pastoris also has an optimal temperature of $60{ }^{\circ} \mathrm{C}$ and $\mathrm{pH}$ of 3.0 [7], which meets the requirements of industrial applications. However, the high cost of phytase remains a barrier to its use in industrial applications. To facilitate the use of C. amalonaticus phytase in industry, high-level expression in an industrial-grade host is necessary.

P. pastoris has become an important tool, especially for heterologous protein production [8]. This methylotrophic yeast is a valuable production system because of its ability to grow to very high cell densities, its ability to produce gram amounts of recombinant proteins per liter of culture both intracellularly and in secretory fashion, and because of the availability of the strong and tightly regulated promoter AOX1 $\left(\mathrm{P}_{A O X 1}\right)$ [9]. The promoter type affects transcription efficiency. Moreover, novel artificial promoters can be assembled by combining cis-acting elements with $\mathrm{P}_{A O X 1}$ to improve the expression of heterologous protein [10]. The Saccharomyces cerevisiae $\alpha$-factor prepro-signal, consisting of a 19-amino acid pre-region signal peptide and a pro-region of 60 hydrophilic amino acids [11], is the most widely and successfully used secretion signal peptide in $P$. pastoris. Optimizing the structure of the $\alpha$-factor [12,13] and choosing endogenous signal peptides, such as the signal peptides of Dse4p [14], may enhance the export of heterologous protein expressed in P. pastoris. Moreover, gene copy number also influences the expression level efficiency [15].

In the natural state, if the expression vector transformed into P. pastoris is a single copy, the probability of the emergence of multi-copy integration is about $10 \%$ and the copy number is not controllable [16]. Therefore, several high-throughput methods have been established to screen a large number of clones for multi-copy integration based on small-scale cultivation [17-19]. Sometimes, high copy number can even be detrimental for recombinant protein productivity [20-22]. Furthermore, high expression of heterologous proteins may cause increasing accumulation of misfolded protein, which then causes endoplasmic reticulum (ER) stress and activates the unfolded protein response (UPR) [23]. Folding and secretion of protein in the ER may be the rate-limiting step in the secretion of a heterologous protein [24, 25]. To overcome these problems, strategies to improve the folding and secretion of proteins have been investigated. Such approaches involved overexpressing the active transcription factor of UPR target gene $H A C 1^{i}$ ( $i$ indicating induced) [26-28], enhancing the expression of the ER chaperone BiP (Kar2p) [29], and increasing expression of disulfide isomerase (Pdilp) [30] and endoplasmic reticulum oxidoreductin 1 (Erolp) [31].

In this study, we used a series of combined genetic modification strategies to enhance production of phytase from C. amalonaticus CGMCC 1696 (Phy) in P. pastoris. These strategies involved modification of $\mathrm{P}_{A O X 1}$, choosing an appropriate signal peptide, and augmentation of the gene dose of AOX1-driven Phy by head-to-tail cassette multimerization. ER stress limits the production of heterologous proteins [32, 33], thus we overexpressed the transcription factor Haclp and the chaperones Pdi1p, Kar2p and Ero1p.

\section{Methods}

\section{Strains and growth conditions}

Escherichia coli TOP10F' (Invitrogen, Carlsbad, CA, USA) cells were used for DNA manipulations; these cells were cultivated in LB or low-salt LB medium. Bacterial plasmid selection and maintenance was performed using $100 \mathrm{mg} / \mathrm{L}$ kanamycin or $25 \mathrm{mg} / \mathrm{L}$ zeocin (Invitrogen). The P. pastoris strain GS115 (Invitrogen) was used as the host cell, and this strain was cultivated in YPD medium $(1 \%$ yeast extract, $2 \%$ peptone, and $2 \%$ glucose). Transformants of P. pastoris were selected on MD (1.34\% YNB, $4 \times 10^{-5} \%$ biotin, $2 \%$ dextrose, and $2 \%$ agar) or YPDSZ plates (1\% yeast extract, $2 \%$ peptone, $2 \%$ glucose, $18.2 \%$ sorbitol, $2 \%$ agar, and $100 \mathrm{mg} / \mathrm{L}$ zeocin). The trace metal solution PTM1 $\left(\mathrm{CuSO}_{4} \cdot 5 \mathrm{H}_{2} \mathrm{O} 0.6 \%, \mathrm{CoCl}_{2} 0.05 \%, \mathrm{FeSO}_{4} \cdot \mathrm{H}_{2} \mathrm{O}\right.$ $6.5 \%$, KI $0.009 \%, \mathrm{H}_{3} \mathrm{BO}_{3} 0.002 \%, \mathrm{H}_{2} \mathrm{SO}_{4} 0.5 \%, \mathrm{MnSO}_{4}$. $\mathrm{H}_{2} \mathrm{O} 0.3 \%, \mathrm{MoNa}_{2} \mathrm{O}_{4} \cdot 2 \mathrm{H}_{2} \mathrm{O} 0.024 \%, \mathrm{ZnCl}_{2} 2 \%$, and biotin $0.02 \%$ ) and basal salt medium (BSM) (glycerol $4 \%$, $\mathrm{CaSO}_{4} 0.093 \%, \mathrm{~K}_{2} \mathrm{SO}_{4} 1.82 \%$, KOH $0.413 \%, \mathrm{MgSO}_{4}$. $7 \mathrm{H}_{2} \mathrm{O} 1.49 \%, \mathrm{H}_{3} \mathrm{PO}_{4} 2.67 \%$, and PTM1 $0.435 \%$ ) were used in fed-batch cultivation. A $50 \%(w / v)$ glycerol solution containing $1.2 \%(v / v)$ PTM1 and methanol containing $1.2 \%(v / v)$ PTM1 were used as feed solutions according to the protocol of the "Pichia Fermentation Process Guidelines" (Invitrogen).

The phytase gene of C. amalonaticus CGMCC 1696, PHY [GenBank: ABI98040.1], was from the vector pPICZ $\alpha A$-phy [7]. The vectors pPICHKA and pPICZA- 
HAC1 were gifts from Dr. Han (South China University of Technology) [22]. The plasmid pTEFZA-EGFP-HIS-G, which contained the GAPDH gene fragment, was from a previous study [14]. Strains, vectors and primers used in the present study are summarized in Additional file 2.

\section{Construction of vectors}

Plasmid construction is illustrated in Additional file 1. The combining of cis-acting elements with $\mathrm{P}_{A O X 1}$ used the same methods as described by Hartner et al. [10]: $5^{\prime}$ arms of $\mathrm{P}_{A O X 1}$ were amplified by PCR using primer pairs AOX F and D1 R or AOX F and 201-2xrv, and the 3' arms using primer pairs AOX R and D1 F or AOX R and 201-2xfw. The $\mathrm{P}_{A O X 1}$ variants were generated using primer pairs AOX F and AOX R (Additional file 2, the $B g l \mathrm{II}$ and BstBI sites are underlined), resulting in the vector $\mathrm{pAOX} 1_{\mathrm{d} 1+201^{-}} \alpha$-phy. To create the plasmids pPICHKA-phy (Phy) and pAOX1 $1_{\mathrm{d} 1+201}-\alpha$-phy-HKA (AOXm), the HIS4 and kanamycin resistance genes from plasmid pPICHKA (HKA) were used to replace the zeocin resistance gene in the plasmids pPICZ $\alpha \mathrm{A}$-phy and

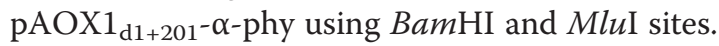

The signal peptide of Dse4p was obtained from P. pastoris strain GS115 genomic DNA using the primer pair SP-D1 and SP-D2 (Additional file 2, the BstBI and EcoRI sites are underlined). The modified $\alpha$-factor with a 10 residue spacer peptide [12] was amplified by PCR using the primer pair SP-M1 and SP-M2 (Additional file 2, the $B s t \mathrm{BI}$ and $E c o$ RI sites are underlined). The modified $\alpha$ factor with a deletion of the predicted third alpha helix was amplified by overlapping PCR: the primer pair SP$\mathrm{M} 1$ and SP- $\Delta 57-70-2$ were used to produce fragment $\Delta 57-70-S P 1$, and the primer pair SP- $\Delta 57-70-1$ and SP$\Delta 2$ were used to generate fragment $\Delta 57-70-\mathrm{SP} 2$. Then, the fragment $\triangle 57-70-\mathrm{SP}$ was amplified by PCR using the fragments $\triangle 57-70-\mathrm{SP} 1$ and $\triangle 57-70-\mathrm{SP} 2$ as template with the primer pair SP-M1 and SP- $\Delta 2$ (Additional file 2, the $B s t \mathrm{BI}$ and EcoRI sites are underlined). All the PCR products were used to replace the $\alpha$-factor gene in the plasmid pAOX1 $1_{\mathrm{d} 1+201^{-}-\alpha \text {-phy, resulting in the vectors }}$ pAOX1 $1_{\mathrm{d} 1+201}$-D-phy, pAOX1 $1_{\mathrm{d} 1+201}-\alpha E 10$-phy, pAOX1 $1_{\mathrm{d} 1}$ $+201^{-} \alpha \Delta 57-70$-phy. Then the zeocin resistance gene in these plasmids was replaced by the HIS4 and kanamycin resistance genes from plasmid pPICHKA using BamHI and MluI sites to create vectors pAOX $1_{\mathrm{d} 1+201}$-D-phyHKA (SP-D), pAOX1 $1_{\mathrm{d} 1+201}-\alpha E 10-$ phy-HKA ( $\left.\alpha E 10\right)$, and pAOX1 $1_{\mathrm{d} 1+201^{-}}-\alpha \Delta 57-70$-phy-HKA ( $\left.\alpha \Delta 57-70\right)$.

Digestion of pPICZA- $\alpha$ E10-phy-HKA with BglII (Thermo Scientific, Waltham, MA, USA) and BamHI (Thermo Scientific) releases the expression cassette $\left(\mathrm{PAOX}_{\mathrm{d} 1+201}\right.$ plus Phy gene, approximately $2700 \mathrm{bp}$, Additional file 3). After production of the BglII-BamHI expression cassette fragment and linearization of pPICZA- $\alpha$ E10-phy-HKA using BamHI, the insert and the plasmid were ligated to obtain the two- copy plasmid pPICZA- $\alpha$ E10-HKA/(Phy $)_{2}$ (2c). A similar method was used to obtain the four-copy and six-copy plasmids, pPICZA- $\alpha$ E10-HKA/(Phy $)_{4}$ (4c) and pPICZA- $\alpha$ E10$\mathrm{HKA} /(\mathrm{Phy})_{6}$ (6c), respectively. The GAPDH gene fragment from the plasmid pTEFZA-EGFP-HIS-G was ligated into the plasmid pPICZaA-phy using the ApaI-NotI sites to create the vector pPICZaA-phy-G. The genes PDI [GenBank: ACF17572.1], KAR2 [GenBank: AAX77226.1] and ERO1 [GenBank: CAY67364.1] were obtained from P. pastoris strain GS115 genomic DNA using appropriate primer pairs (Additional file 2, the PmlI and SacII sites are underlined). All the PCR products were ligated into the plasmid pPICZA (Invitrogen) using the PmlI-SacII sites to create vectors pPICZA-PDI, pPICZA-KAR2, and pPICZA-ERO1. Restriction enzyme digestion and DNA sequencing assured that all plasmids matched their designs (data not shown).

\section{Yeast transformation}

Plasmids HKA, Phy, AOXm, SP-D, $\alpha E 10, \alpha \Delta 57-70,2 c$, $4 c$, and $6 \mathrm{c}$ were linearized with Kpn2I (Thermo Scientific), whose cleavage site was located in the his4 sequence, and transformed into P. pastoris GS115 competent cells using the standard lithium chloride transformation method according to the manufacturer's protocol (Invitrogen). The transformed cells were selected on MD plates and incubated at $30{ }^{\circ} \mathrm{C}$ for 3 days. Recombinants of GS115/ $\alpha$ E10 were selected on plates with MD medium containing G418 at 1, 2, 5, 7, and $9 \mathrm{mg} / \mathrm{mL}$. The integration of the recombinant plasmid, $\alpha \mathrm{E} 10$, into the GS115 genome was verified by colony PCR using 5'AOX1 and $3^{\prime}$ AOX1 as the sequencing primers (data not shown).

The plasmids pPICZA-HAC1, pPICZA-PDI, pPICZAKAR2, and pPICZA-ERO1 were linearized with MssI (Thermo Scientific), whose cleavage site was located in the $A O X 1$ promoter sequence, and transformed into GS115/6c competent cells. The transformed cells were selected on YPDSZ plates and incubated at $30{ }^{\circ} \mathrm{C}$ for $3-$ 4 days. The integration of the recombinant plasmids into the GS115/6c genome was verified by colony PCR using 5'AOX1 and HAC-A, PDI-2, KAR2-2, or ERO-2 as the sequencing primers (data not shown).

\section{Determination of the phy copy number by quantitative PCR} The quantitative PCR (qPCR) assay protocol was derived from the Pfaffl method [34]. The plasmid pPICZ $\alpha A-p h y-G$, consisting of a portion of the GAPDH gene and the following genomic sequence, was used as the reference sequence because there is only a single copy in the $P$. pastoris genome [35]. Genomic DNA was extracted from P. pastoris using the Yeast DNAiso-Kit (Takara, Shiga, Japan) according to the manufacturer's manual. RT-Phy1/RT-Phy2 and RT-G1/RT-G2 were used as primers at concentrations of $400 \mathrm{nM}$ with genomic DNA as the template. The yeast 
recombinant DNA and the standard plasmid were analyzed simultaneously using SYBR Premix Ex Taq ${ }^{\text {Tw }}$ II (Tli RNaseH Plus) (Takara) in an Applied Biosystems 7500 fast real-time PCR instrument (Applied Biosystems Inc., Foster City, CA, USA). The qPCR assay was repeated three times for one sample. The copy number of phy in each transformant was calculated using the $\mathrm{Ct}$ value of the $P$. pastoris genomic DNA and a standard curve. The Phy gene copy number in the $P$. pastoris genome was determined with the following equation:

$$
\text { phy gene copy number }=\frac{\begin{array}{c}
p h y \text { gene copy number calculated } \\
\text { by standard curve }
\end{array}}{\begin{array}{c}
\text { GPADH fragment copy number } \\
\text { calculated by standard curve }
\end{array}}
$$

\section{Cultivation of $P$. pastoris and expression of phytase}

$P$. pastoris transformants were inoculated into $5 \mathrm{~mL}$ of BMGY medium (1 \% yeast extract, $2 \%$ peptone, $1.34 \%$ YNB, $0.00004 \%$ biotin, $100 \mathrm{mM}$ potassium phosphate (pH 6.0), and $1 \%$ glycerol) in a 50-mL Erlenmeyer flask. The cells were precultivated overnight at $30{ }^{\circ} \mathrm{C}$ and $250 \mathrm{rpm}$. Next, the main cultures were inoculated from precultures to obtain an initial optical density of 0.5 . The cells were grown in $20 \mathrm{~mL}$ of BMMY medium (1\% yeast extract, $2 \%$ peptone, $1.34 \% \mathrm{YNB}, 0.00004 \%$ biotin, $100 \mathrm{mM}$ potassium phosphate ( $\mathrm{pH} 6.0$ ), and $1 \%$ methanol) in a $250-\mathrm{mL}$ Erlenmeyer flask in a shaking incubator at $30{ }^{\circ} \mathrm{C}$ and $250 \mathrm{rpm}$. Fresh methanol was added to obtain a final concentration of $1 \%(v / v)$ every $24 \mathrm{~h} . \mathrm{OD}_{600}$ and phytase activity were monitored throughout a 5-day incubation.

The fermentation of the recombinant $P$. pastoris was performed in a 10-L standard fermenter (FUS10-A, Shanghai Guoqiang Bioengineering Equipment Co., Ltd., Shanghai, China) containing 5 L BSM. The cultivation parameters of the fermenter were as follows: growth temperature $30{ }^{\circ} \mathrm{C}$, growth $\mathrm{pH} 5.5$, air flow rate $10 \mathrm{~L} / \mathrm{min}$, and stirring speed $800 \mathrm{rpm}$. Typical recombinant $P$. pastoris fermentation comprised three phases. The entire cultivation started with a batch phase (phase I) in BSM for initial cell growth; this phase lasted for about $18-24 \mathrm{~h}$ at $30{ }^{\circ} \mathrm{C}$ and pH5.5. After the glycerol in the medium was exhausted, the fed-batch phase (phase II) was initiated by feeding limited glycerol to allow further cell growth. When $\mathrm{OD}_{600}$ reached approximately 230, glycerol feeding was ended and there was a carbonsource starvation period of $30 \mathrm{~min}$ to allow complete consumption of the glycerol and its mesostates. At the same time, the temperature was reduced to $25^{\circ} \mathrm{C}$ and the $\mathrm{pH}$ of the broth was adjusted to 6.0 by adding ammonia solution $(25 \%, v / v)$. The induction phase (phase III) was started by the addition of 10-15 g/h mixtures of glycerol and methanol $(100 \%$ methanol: $50 \%$ glycerol $=2: 1, v / v)$ as carbon source. The mixture feed rate was then adjusted upwards every $1.5-2 \mathrm{~h}$ until reaching $40 \pm 2 \mathrm{~g} / \mathrm{h}$, while dissolved oxygen (DO) was kept constant at about $20-30 \%$. OD 600 and phytase activity were monitored throughout a 7-day induction.

\section{Phytase enzymatic activity}

Phytase activity was analyzed according to the method described by Žyla [36], with modifications. Fifty microliters of culture were centrifuged for $1 \mathrm{~min}$ at $8000 \mathrm{rpm}$ and room temperature. The supernatants were diluted with $100 \mathrm{mM}$ sodium acetate buffer (pH5.5) to reach a volume of $1 \mathrm{~mL}$, and the mixture was preheated at $37{ }^{\circ} \mathrm{C}$ for $5 \mathrm{~min}$. Next, $2 \mathrm{~mL}$ of $5.0 \mathrm{mM}$ sodium phytate (pH 5.5) was added and the mixture was incubated at $37^{\circ} \mathrm{C}$ for $30 \mathrm{~min}$, then $2 \mathrm{~mL}$ of coloration solution [ $24 \%$ nitric acid, $100 \mathrm{~g} / \mathrm{L}$ ammonium molybdate, and $2.35 \mathrm{~g} / \mathrm{L}$ ammonium vanadate, 2:1:1 (v/v/v)] was added and incubated for $10 \mathrm{~min}$. The absorbance of the mixture was measured at $415 \mathrm{~nm}$. One unit of activity (U) was defined as the amount of enzyme that hydrolyzed $5.0 \mathrm{mM}$ sodium phytate per min to generate $1 \mu \mathrm{mol}$ of inorganic phosphorus at $37^{\circ} \mathrm{C}$. All values are averages obtained from three independent experiments and use GS115/HKA as background (control) samples.

\section{SDS-PAGE and protein content analysis}

After induction, sodium dodecyl sulfate polyacrylamide gel electrophoresis (SDS-PAGE) was performed on culture supernatants using $12 \%$ SDS-polyacrylamide gels. The supernatants of strain GS115/Phy were treated with PNGase F (NEB, Boston, MA, USA). Supernatant was heatdenatured by treating at $100{ }^{\circ} \mathrm{C}$ for $5 \mathrm{~min}$ in denaturing buffer containing $1 \%$ SDS and $0.5 \%$ 2-mercaptoethanol. The proteins were stained with Coomassie Brilliant Blue R-250 (Invitrogen).

The phytase concentration in the supernatants was estimated by SDS-PAGE with bovine serum albumin (BSA; Invitrogen) as the standard. The amount of Phy in supernatants expressed by $P$. pastoris was quantified with equal volumes of BSA of known concentrations as an external reference protein and the Phy band was analyzed using Quantity One software (Bio-Rad, CA, USA).

\section{Genetic stability of recombinant $P$. pastoris}

To demonstrate the stable inheritance and stable expression levels of the phytase genes in progenies [37], clones of the strain $6 \mathrm{c} / \mathrm{HAC} 1$ were grown on rich YPD selective medium for 10 cycles. After the first culture reached the stationary phase of growth on YPD medium, $1 \%$ culture was inoculated into new 100-ml YPD medium for the next cycle of growth. This was repeated for ten cycles. Phytase activity and PHY copy number were determined in the strain after 10 sub-cultivations. 


\section{Results}

\section{Construction of phytase expression system}

Plasmid construction in this work is illustrated in Additional file 1. The vector pPICZ $\alpha$ A-phy [7], which carries the phytase gene of C. amalonaticus CGMCC 1696, had the zeocin resistance gene replaced by the HIS4 and kanamycin resistance genes from plasmid pPICHKA [22] to create plasmid pPICHKA-phy (Phy). The combination of cis-acting elements with $\mathrm{P}_{A O X 1}$, a deletion of $\mathrm{P}_{A O X 1}$ nucleotides -777 and -712 and the addition of -203 and -190 [10], was performed to create plasmid pAOX $1_{\mathrm{d} 1+201^{-}} \alpha$-phy-HKA (AOXm). Based on this plasmid, a 10-residue spacer peptide (EEAEAEAEPK) between the $\alpha$-factor prepro-signal [13] and the phytase gene was introduced to create plasmid pAOX $1_{\mathrm{d} 1+201}-\alpha E 10$-phyHKA ( $\alpha E 10)$; a deletion of the predicted third alpha helix of the $\alpha$-factor [12] was performed to create plasmid pAOX $1_{\mathrm{d} 1+201}-\alpha \Delta 57-70$-phy-HKA $(\alpha \Delta 57-70)$; and replacement of the $\alpha$-factor by the signal peptide of Dse4p [14] was undertaken to create plasmid $\mathrm{pAOX} 1_{\mathrm{d} 1+201}-\mathrm{D}$-phyHKA (SP-D). Based on the plasmid $\alpha E 10$, plasmids pPICZA- $\alpha$ E10-HKA/(Phy) $)_{2}$ (2c), pPICZA- $\alpha$ E10-HKA/(Phy $)_{4}$ (4c), and pPICZA- $\alpha$ E10-HKA/(Phy) 6 (6c) were created, which contained two, four and six expression cassettes respectively (Additional files 1 and 3).

All plasmids were transformed into P. pastoris GS115 after linearization with Kpn2I; the resulting strains were designated GS115/HKA, GS115/Phy, GS115/AOXm, GS115/ $\alpha$ E10, GS115/ $\alpha \Delta 57-70$, GS115/SP-D, GS115/2c, GS115/4c and GS115/6c. The recombinant strains of GS115/ $\alpha$ E10 were selected on MD plates supplemented with different concentrations of the aminoglycoside antibiotic G418 to obtain strains containing high copy numbers (GS115/nc). The plasmids pPICZA-HAC1, pPICZA-PDI, pPICZA-KAR2, and pPICZA-ERO1 were transformed into recombinant strain GS115/6c after linearization with $M s s I$ to form strains $6 \mathrm{c} / \mathrm{HAC1}, 6 \mathrm{c} / \mathrm{PDI}$, 6c/KAR2, and 6c/ERO1.

\section{Gene copy number determination by quantitative PCR}

The copy number of target genes can significantly influence the production of recombinant protein, and neglecting gene copy number can easily lead to an incorrect interpretation of experimental results concerning codon optimization, promoter studies, co-expression of helper proteins, and signal peptide optimization [38]. Therefore, qPCR assays were performed to precisely determine the Phy gene copy number in the genomes of the integrants.

The Phy gene copy numbers of strains GS115/Phy, GS115/AOXm, GS115/ $\alpha$ E10, GS115/ $\alpha \Delta 57-70$, and GS115/ SP-D, normalized to the reference GAPDH gene fragment [35], were 0.997, 0.989, 0.998, 0.982, and 0.984, respectively (Additional file 4 ). These results indicate that the strains above contained a single copy of the
Phy gene, ruling out the influence of copy number on the secretion of Phy. The strains GS115/2c, GS115/4c, and GS115/6c were confirmed to contain two, four, and six copies of $P H Y$ respectively (Fig. 1). We also obtained some high copy number integrants under the pressure of G418, carrying seven, eight, ten, and 15 copies of the Phy gene (Fig. 1).

\section{Phy expression in $P$. pastoris}

After $96 \mathrm{~h}$ of induction with methanol, the phytase obtained reached the maximum observed level. The phytase activity and protein content of strain GS115/Phy were $414 \mathrm{U} / \mathrm{mL}$ and $0.13 \mathrm{~g} / \mathrm{L}$ (Fig. 2a). Figure $2 \mathrm{~b}$ shows that the molecular weight of recombinant phytase was approximately $50 \mathrm{kDa}$, assayed by SDS-PAGE. There were several bands visible on SDS-PAGE on separation of Gs115/Phy supernatants, but after PNGase F treatment there was only one band, of nearly $43 \mathrm{kDa}$, which was similar to that described by Luo et al. [6]. This suggested that the phytase protein was partially glycosylated in P. pastoris and the observed molecular weights were higher than the molecular weight predicted from the amino acid sequence alone (46.3 kDa).

\section{Combined strategies for enhancement of Phy expression in $P$. pastoris}

After $96 \mathrm{~h}$ of induction with methanol, the phytase obtained reached the maximum observed level for all recombinant strains (data not shown). Modification of the putative cis-acting region of $\mathrm{P}_{A O X 1}$ nucleotides, i.e., deleting -777 and -712 and adding -230 and -190 , resulted in an increase in phytase activity of about $35 \%$, reaching $560 \mathrm{U} / \mathrm{mL}$ (Fig. 3a), which was similar to the results of Hartner et al. [10].

Among all the modifications of the signal peptide, only the addition of a 10-residue spacer peptide (EEAEAEAEPK) between the $\alpha$-factor prepro-signal and the phytase gene increased yield, by $12 \%$ relative to that of the $\alpha$-factor signal peptide alone, to $626 \mathrm{U} / \mathrm{mL}$ (Fig. 3a).

In the high copy number integrants, Phy productivity increased with the gene copy number up to a maximum of six copies; the phytase activity of strain GS115/6c increased $141 \%$ (reached $1511 \mathrm{U} / \mathrm{mL}$, Fig. 3a) relative to the corresponding single-copy strains, but then there was a plateau effect when the copy number was increased further (Fig. 3a and Additional file 5).

On further modifying strain GS115/6c, overexpression of Pdilp and Erolp enhanced Phy secretion by 27 and 20.6 \% (Fig. 3a), respectively. Overexpression of Hac1p improved phytase activity by $40 \%$ relative to that for strain GS115/6c; it reached $2119 \mathrm{U} / \mathrm{mL}$ (Fig. 3a), which was similar to the effect observed when overexpression of Hac1p enhanced Bacillus amyloliquefaciens $\alpha$-amylase secretion in S. cerevisiae [27] and secretion of xylanase A from Bacillus halodurans C-125 in P. pastoris [28]. 

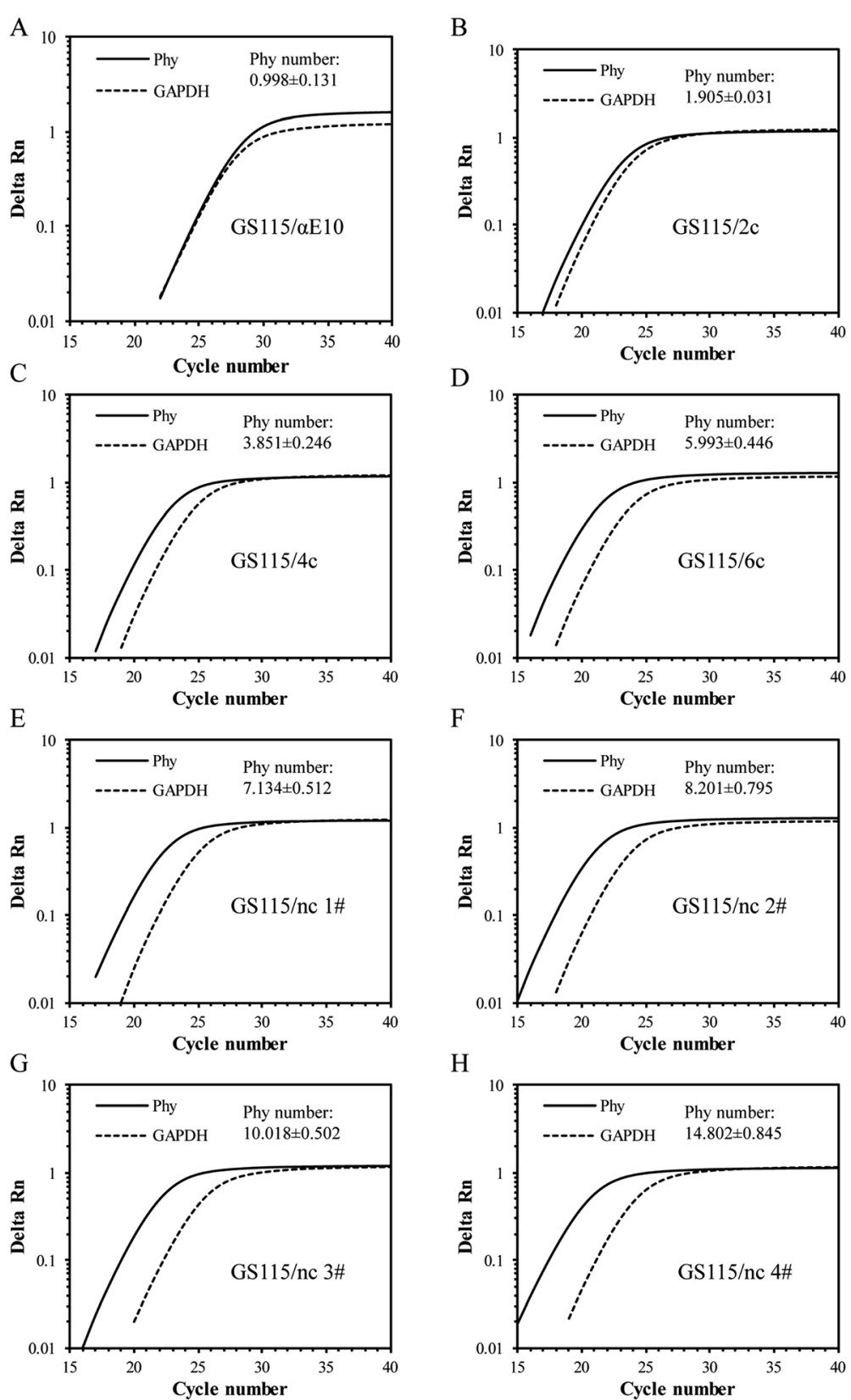

Fig. 1 Quantitative PCR assay of the PHY copy number in recombinant yeast strain genomic DNA. The threshold value (horizontal dashed line) was set at 0.2. The values indicate the average \pm standard deviations from three independent $\mathrm{QPCR}$ experiments

On combination of all of the methods used above to improve Phy expression, the phytase activity and protein content of strain $6 \mathrm{c} / \mathrm{HAC} 1$ finally reached $2119 \mathrm{U} / \mathrm{mL}$ (Fig. 3a) and $0.75 \mathrm{~g} / \mathrm{L}$ (Fig. $3 \mathrm{~b}$ and c) in $250-\mathrm{mL}$ shaken flasks, an increase of $412 \%$ relative to the original strain GS115/Phy.

\section{Phytase production by the recombinant strains in a bench-top fermenter}

The Phy-producing capacity of strain $6 \mathrm{c} / \mathrm{HAC} 1$ was evaluated further by high-density fermentation in a $10-\mathrm{L}$ fermenter. Prepared liquid seeds were inoculated into the fermenter and the induction phase was started when the $\mathrm{OD}_{600}$ reached 230 (Fig. 4a). After induction for about $120 \mathrm{~h}$, the highest observed recombinant phytase activity and protein content reached $35,032 \mathrm{U} / \mathrm{mL}$ and $9.58 \mathrm{~g} / \mathrm{L}$ (Fig. $4 \mathrm{a}$ and b).

\section{Genetic stability}

Figure 5 and Additional file 6 show that the phytase activity and $P H Y$ copy number of strain $6 \mathrm{c} / \mathrm{HAC} 1$ was not significantly different after ten cultivations compared 


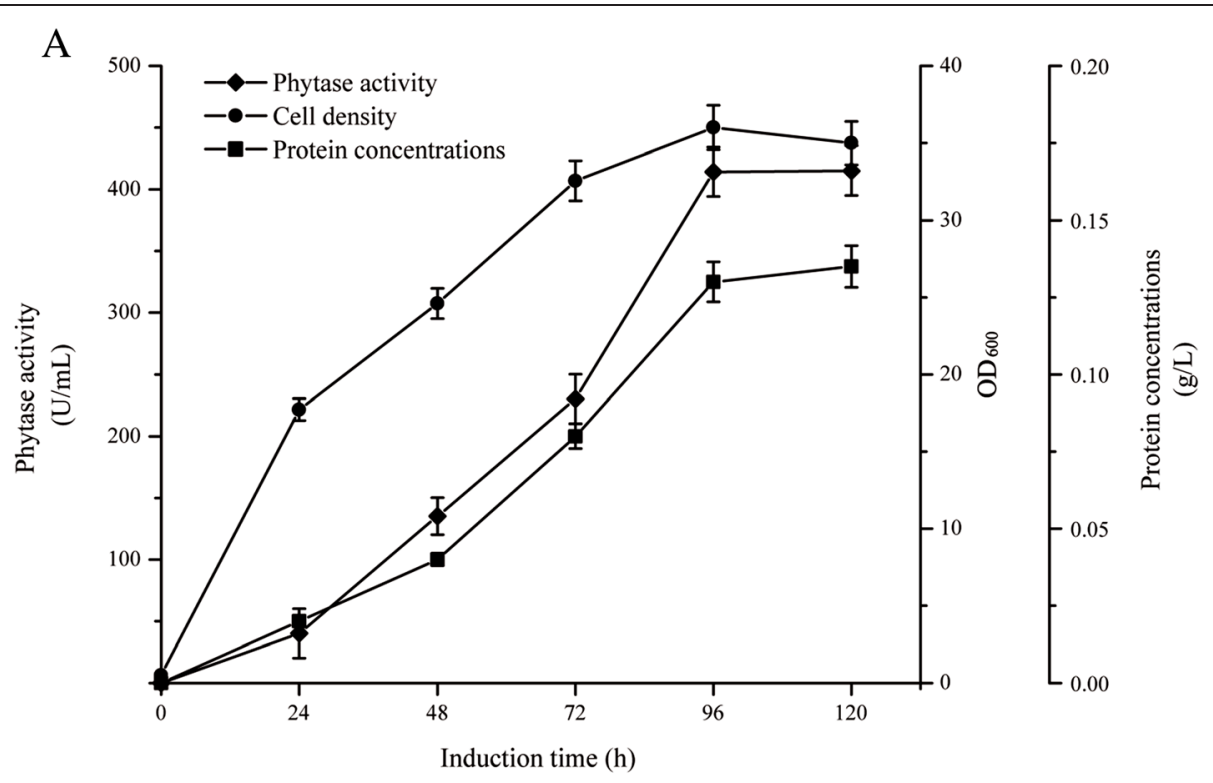

B

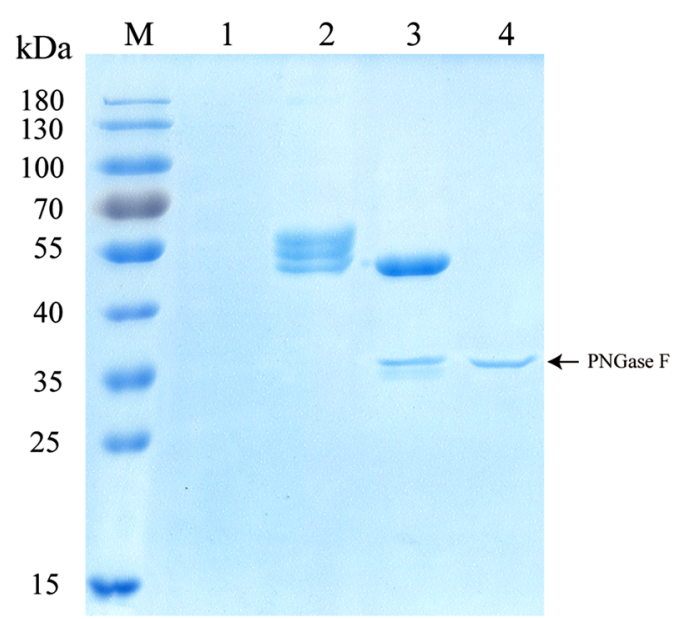

Fig. 2 Expression of the phytase from C. amalonaticus CGMCC 1696 in P. pastoris. a: Time dependence of the activity of phytase, cell growth and phytase protein content of Gs115/Phy after induction with methanol, using GS115/HKA as the background (control) sample. b: SDS-PAGE assay of the culture supernatant containing C. amalonaticus CGMCC 1696 phytase (stained with Coomassie Blue) after methanol induction for 96 h. Lane 1: culture supernatants from recombinant $P$. pastoris GS115/HKA; lane 2: culture supernatants from recombinant $P$. pastoris Gs 115/Phy; lane 3: culture supernatants from recombinant P. pastoris Gs115/Phy after PNGase F treatment; lane 4: culture supernatants from recombinant $P$. pastoris GS115/HKA after PNGase F treatment

with the original colony. This indicated that the plasmids were highly stable during the sub-cultivations of the $P$. pastoris GS115 transformant at $30{ }^{\circ} \mathrm{C}$ in YPD medium. The genetic stability of the recombinant protein in this study was similar to that of the A. niger SK-27 phyA gene with the MF4I signal peptide expressed in $P$. pastoris, which retained $98 \%$ of the phytase yield after ten cultivations [37].

\section{Discussion}

All the strains of the signal peptide modifications have the same Phy gene copy number (Additional file 4), indicating that the insertion of a spacer peptide worked well with the $\alpha$-factor and $P H Y$ and thus enhanced Phy secretion in $P$. pastoris. However, replacement of the reporter gene of EGFP by $P H Y$, a deletion of the predicted third alpha helix of the $\alpha$-factor, and replacement of the $\alpha$-factor by the signal peptide of Dse4p did not work well, in contrast to the results of Lin-Cereghino et al. [12] and Liang et al. [14], which indicated that different signal peptides may have different secretion efficiencies with different proteins. The signal peptide determines whether co-translational translocation or post-translational translocation occurs for entrance to the ER and 


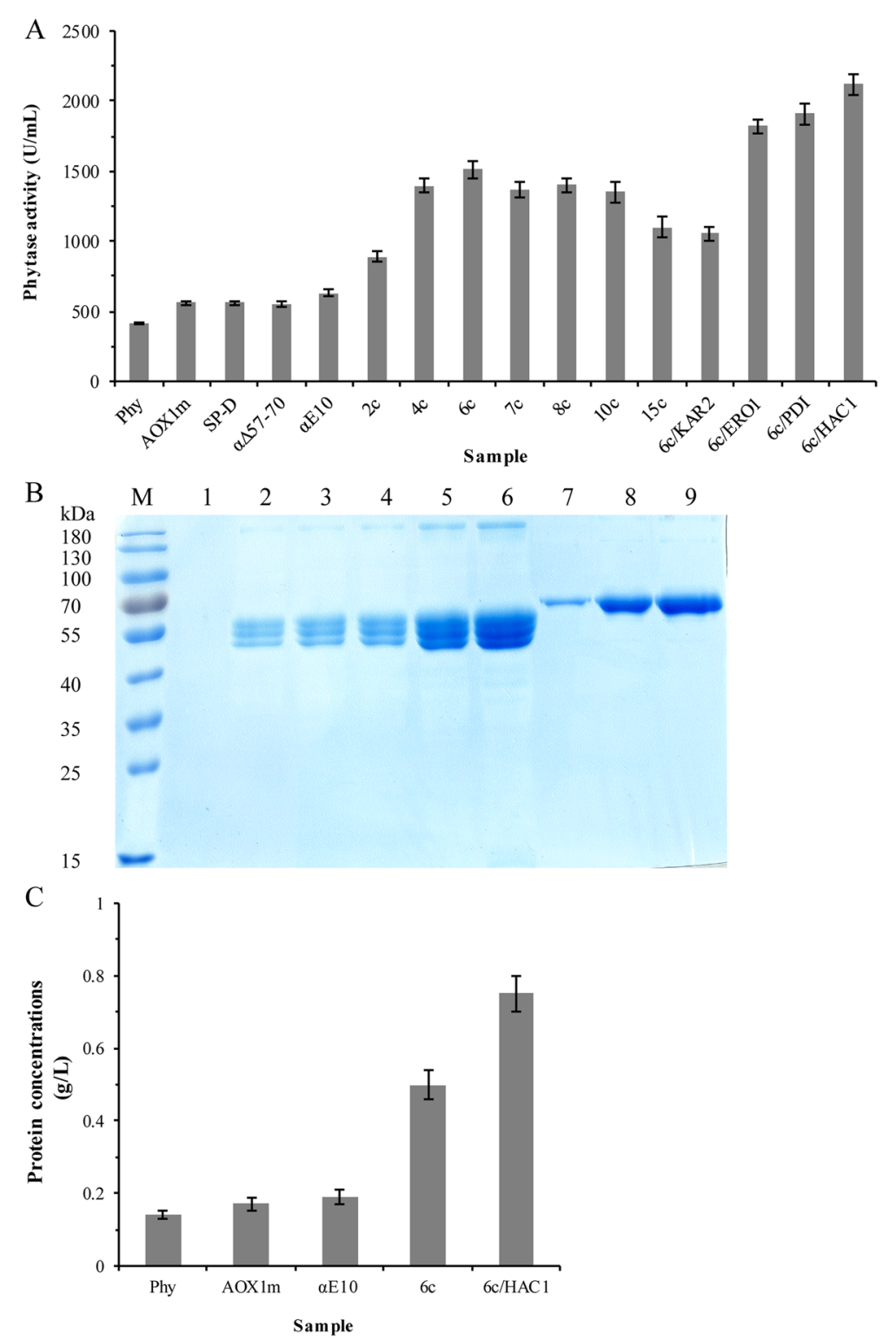

Fig. 3 Different tactics for enhancing the expression of Phy in $P$. pastoris. a: Effect of modification of $P_{A O X}$ and the signal peptide, increasing gene copy number, and overexpression of Kar2p, Erolp, Pdi1p, or Hac1p on phytase production in recombinant strains carrying six Phy gene copies after 96-h induction with methanol. All activities used GS115/HKA as the background measurement. b: SDS-PAGE assay of the collected culture supernatant from the most effective strains after 96-h induction with methanol. Lane M: protein marker; lane 1: GS1 15/HKA; lane 2: GS115/Phy; lane 3: GS115/AOXm; lane 4: GS115/aE10; lane 5: GS115/6c; lane 6: 6c/HAC1; lane 7: 0.05 mg/mL BSA; lane 8: 0.2 mg/mL BSA; lane 9: 0.3 mg/mL BSA. c: The phytase protein content of the most effective strains after 96-h induction with methanol

the secretion efficiency is related to the characteristics of the heterologous protein and the signal peptide [39].

Increasing gene copy numbers improved phytase expression obviously (Fig. 3a and Additional file 5). But when the copy number was increased further, there was a plateau effect (Fig. 3a and Additional file 5). It is plausible that direct correlation of expression level and gene copy number is not necessarily valid when the protein is directed to the secretory pathway. In that case, the production of a secreted protein will reach its limit at a specific gene copy number where further increases in transcription and translation due to the higher abundance of gene copies will not enhance the secretion process any further [40, 41].

Several studies have been conducted on high expression of phytase in $P$. pastoris. By codon usage optimization and $\alpha$-factor modification, the phytase activity and protein content of Peniophora lycii phytase reached $10540 \mathrm{U} / \mathrm{mL}$ and $12.2 \mathrm{~g} / \mathrm{L}$ in a 5 - $\mathrm{L}$ fermenter [42]. A. niger SK-57 phytase was modified by using 


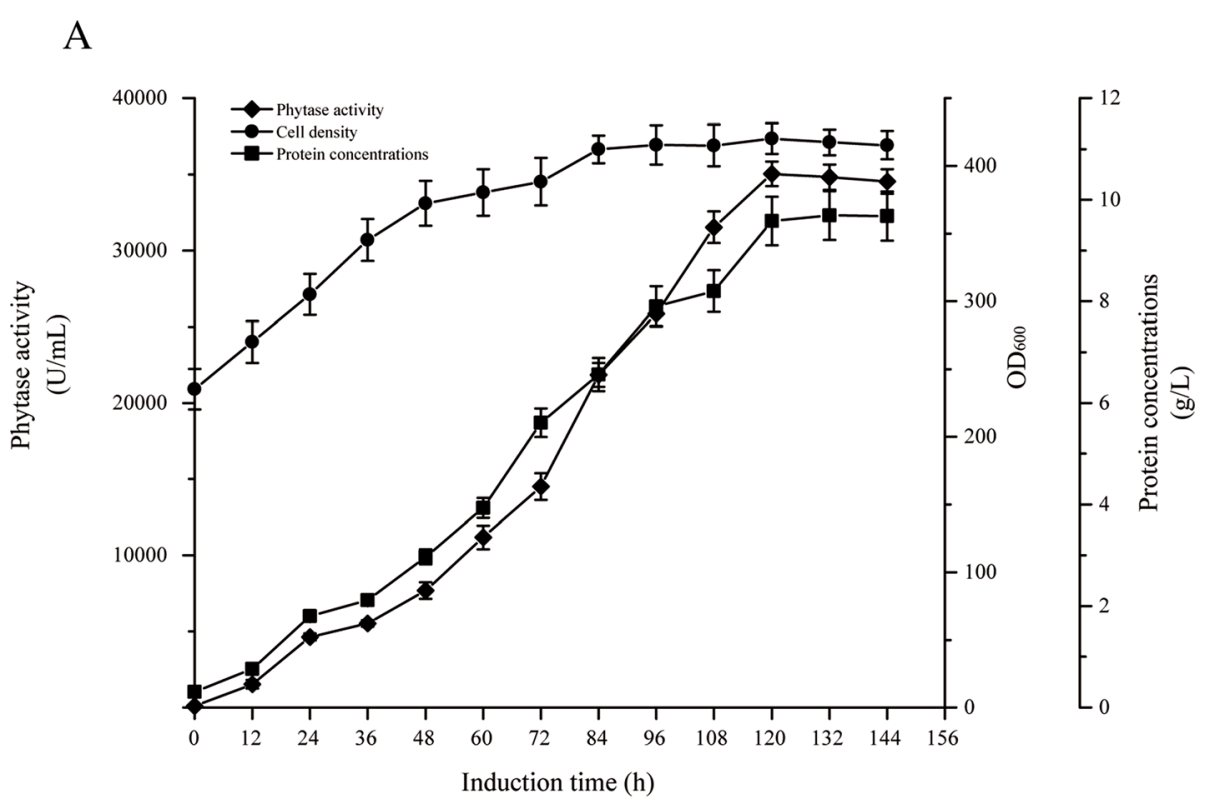

B

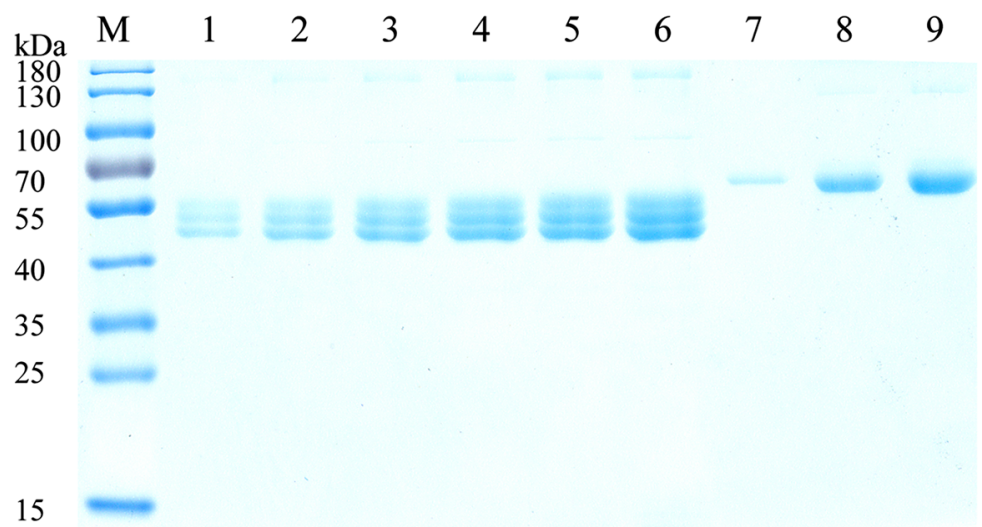

Fig. 4 Growth and phytase production time course of P. pastoris $6 \mathrm{C} / \mathrm{HAC} 1$ in a 10-L fermenter. a: Time dependence of phytase activity, cell density and phytase protein content after induction with methanol. The phytase activity was detected using collected culture supernatant. The sample was boiled for 10 min was used as the background sample. b: SDS-PAGE assay of the collected culture supernatant. All the collected supernatants were diluted 1:40 with $100 \mathrm{mM}$ sodium acetate buffer (pH5.5) (v/V). Lane M: protein marker; lane 1: induction for 24 h; lane 2: induction for 48 h; lane 3 : induction for $72 \mathrm{~h}$; lane 4: induction for $96 \mathrm{~h}$; lane 5: induction for $120 \mathrm{~h}$; lane 6: induction for $144 \mathrm{~h}$; lane 7: $0.05 \mathrm{mg} / \mathrm{mL}$ BSA; lane 8: 0.2 mg/mL BSA; lane 9: $0.3 \mathrm{mg} / \mathrm{mL}$ BSA

successive polymerase chain reactions and deleting intronic sequences, optimizing codon usage, and $\alpha$-factor modification; phytase activity reached $865 \mathrm{U} / \mathrm{mL}$ and 6.1 $\mathrm{g} / \mathrm{L}$ of protein content in a 2-L fermenter [37]. By changing transgene copy number, codon bias, sequence optimization, and temperature during expression, Lillium longiflorum phytase levels increased 1.2-20-fold [43]. However, most of these studies only solved a problem in one protein synthesis pathway, which will result in a bottleneck in another pathway. When larger amounts of polypeptides are processed in the ER, some are misfolded and degraded [21].
Here, overexpression of Haclp, Pdilp, and Erolp enhanced the expression of Phy (Fig. 3a and c). Overexpression of Pdilp and Erolp increased disulfide bond formation activity [33]. Pdilp behaves as a chaperone, inhibiting the aggregation of misfolded proteins [44]. Overexpression of Pdilp enhanced expression of several heterologous proteins in S. cerevisiae [30, 45] and P. pastoris [46-48]. Overexpression of Ero1p enhanced the secretion of single-chain T-cell receptor (scTCR) in $S$. cerevisiae [49] and Fab fragment secretion in $P$. pastoris [48]. However, in our work, overexpression of Kar2p decreased the expression of Phy, similar to observations on 


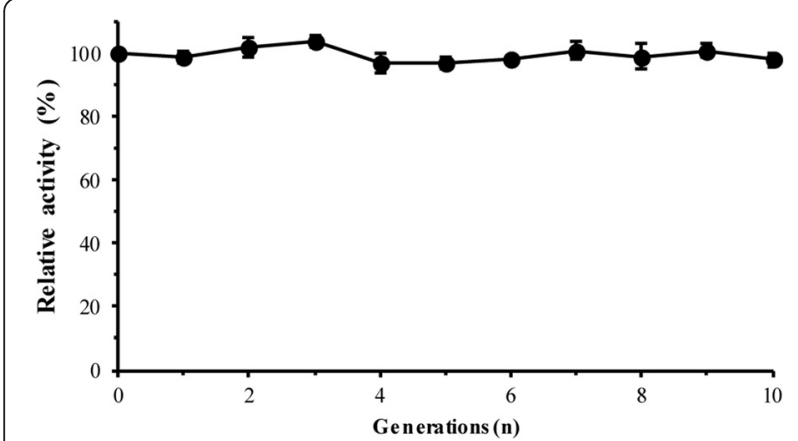

Fig. 5 Changes in phytase activity of strain $6 \mathrm{c} / \mathrm{HAC} 1$ after ten cultivations. The phytase activity of strain $6 \mathrm{c} / \mathrm{HACl}$ after ten sub-cultivations with 96-h methanol induction. All activities were compared with the activity of the original clone, with GS115/HKA as the background sample

Schizosaccharomyces pombe acid phosphatase expression in S. cerevisiae [50], but different from antithrombotic hirudin expression in S. cerevisiae [29] and Fab fragment secretion in P. pastoris [48]. The effects of overexpression of Kar2p seem to depend on the target recombinant protein. Overexpression of Haclp enhances the expression of chaperones (e.g., Pdilp) and affects many important cellular processes, including carbon metabolism, stress response and protein folding, enhancing protein secretion [51]. Thus Hac1p overexpression may solve the ER bottleneck in protein synthesis and increase the expression of heterologous proteins $[27,28]$. Enhancement of protein folding in the ER can alleviate bottlenecks in the folding and secretion pathways during the overexpression of heterologous proteins in $P$. pastoris $[21,52]$.

\section{Conclusions}

Using modifications of $\mathrm{P}_{A O X I}$ and the $\alpha$-factor signal peptide, increased gene copy number, and overexpression of Haclp to enhance folding and secretion of the protein in the endoplasmic reticulum, we have successfully increased the yield of C. amalonaticus CGMCC 1696 phytase in P. pastoris to $412 \%$ of that for the original strain, Gs115/ Phy. In a 10-L fed-batch fermenter, the phytase yield achieved was $9.58 \mathrm{~g} / \mathrm{L}$, with an activity of $35,032 \mathrm{U} / \mathrm{mL}$; production of phytase can be directed towards different biocatalytic and feed additive applications.

\section{Additional files}

Additional file 1: Figure S1. The construction of plasmids used in this study. A: Construction of the plasmids containing modified promoters and different signal peptides; B: Construction of the plasmids containing different copy numbers of PHY; C: Construction of the plasmids containing a GAPDH fragment; D: Construction of the plasmids containing different chaperone proteins and HAC1. (PDF $914 \mathrm{~kb}$ )
Additional file 2: Table S1. Primers, vectors and strains used in this study. (PDF 254 kb)

Additional file 3: Figure S2. Restriction enzyme digestion of plasmids containing two, four, and six expression cassettes. The plasmid $2 c$ was digested using Bg/ll, BamHI, and Kpn2l, and the plasmids aE10, 4c, and $6 \mathrm{c}$ using $\mathrm{Bg} / \mathrm{ll}$ and $\mathrm{BamHI}$. The results of the restriction enzyme digestion were visualized using a $1 \%$ (wet $w / V$ ) agarose gel. (PDF $111 \mathrm{~kb}$ )

Additional file 4: Figure S3. Quantitative PCR assay of the Phy copy number in genomic DNA of recombinant yeast strains GS115/Phy, GS115/AOXm, GS115/SP-D, GS115/aE10 and GS115/a $\triangle 57-70$. The threshold value (horizontal dashed line) was set at 0.2. The values indicate the average \pm standard deviations from three independent $\mathrm{qPCR}$ experiments. (PDF $273 \mathrm{~kb}$ )

Additional file 5: Figure S4. The phytase activity of strains containing different PHY copy numbers after induction for 96 h, using GS115/HKA as the background sample. (PDF $82 \mathrm{~kb}$ )

Additional file 6: Figure S5. Quantitative PCR assay of the Phy copy number in genomic DNA of recombinant yeast strain $6 \mathrm{c} / \mathrm{HAC} 1$ after ten sub-cultivations. The threshold value (horizontal dashed line) was set at 0.2. The values indicate the average \pm standard deviations from three independent qPCR experiments. (PDF $291 \mathrm{~kb}$ )

\section{Competing interests}

The authors declare that they have no competing interests.

\section{Authors' contributions}

LSL, LY and LC carried out project design. LC and ZXY carried out gene cloning, sequence analysis and vector construction. LC, PN, LXH, LXX and HYY carried out $P$. pastoris transformation, expression and enzyme determination. LC and LSL coordinated the project, supervised its development and wrote the final manuscript. All authors read and approved the final manuscript.

\section{Authors' information}

Not applicable.

\section{Acknowledgements}

We appreciate Dr. Shuangyan Han for the vectors PPICHKA and PPICZAHAC1.

\section{Funding}

This is financially supported by the National Science Foundation for Young Scientists of China (Grant No.31400062), National Natural Science Foundation of China (Grant No.31470159), National science and technology support project (Grant No. 2013BAD10B01) and Fundamental Research Funds for the Central Universities (Grant No. 2014ZB0013).

Received: 12 May 2015 Accepted: 9 September 2015

Published online: 26 September 2015

\section{References}

1. Lei X, Stahl C. Biotechnological development of effective phytases for mineral nutrition and environmental protection. Appl Microbiol Biotechnol. 2001;57(4):474-81.

2. Jorquera M, Martínez $O$, Maruyama F, Marschner $P$, de la Luz MM. Current and future biotechnological applications of bacterial phytases and phytaseproducing bacteria. Microbes Environ. 2008;23(3):182-91.

3. Augspurger N, Webel D, Lei X, Baker D. Efficacy of an E. coli phytase expressed in yeast for releasing phytate-bound phosphorus in young chicks and pigs. J Anim Sci. 2003:81(2):474-83.

4. Chen C-C, Wu P-H, Huang C-T, Cheng K-J. A Pichia pastoris fermentation strategy for enhancing the heterologous expression of an Escherichia coli phytase. Enzym Microb Technol. 2004;35(4):315-20

5. Krishna C, Nokes S. Predicting vegetative inoculum performance to maximize phytase production in solid-state fermentation using response surface methodology. J Ind Microbiol Biotechnol. 2001;26(3):161-70.

6. Luo $H$, Huang $H$, Yang $P$, Wang $Y$, Yuan $T$, Wu N, et al. A novel phytase appA from Citrobacter amalonaticus CGMCC 1696: gene cloning and overexpression in Pichia pastoris. Curr Microbiol. 2007;55(3):185-92. 
7. Li C, Lin Y, Huang Y, Liu X, Liang S. Citrobacter amalonaticus Phytase on the Cell Surface of Pichia pastoris Exhibits High pH Stability as a Promising Potential Feed Supplement. PLoS One. 2014;9(12):e114728.

8. Kurtzman CP. Biotechnological strains of Komagataella (Pichia) pastoris are Komagataella phaffii as determined from multigene sequence analysis. J Ind Microbiol Biotechnol. 2009;36(11):1435-8.

9. Cregg JM, Barringer K, Hessler A, Madden K. Pichia pastoris as a host system for transformations. Mol Cell Biol. 1985;5(12):3376-85.

10. Hartner FS, Ruth C, Langenegger D, Johnson SN, Hyka P, Lin-Cereghino GP, et al. Promoter library designed for fine-tuned gene expression in Pichia pastoris. Nucleic Acids Res. 2008;36(12):e76.

11. Kurjan J, Herskowitz I. Structure of a yeast pheromone gene (MFa): A putative a-factor precursor contains four tandem copies of mature a-factor. Cell. 1982;30(3):933-43.

12. Lin-Cereghino GP, Stark CM, Kim D, Chang J, Shaheen N, Poerwanto H, et al. The effect of a-mating factor secretion signal mutations on recombinant protein expression in Pichia pastoris. Gene. 2013;519(2):311-7.

13. Kjeldsen T, Pettersson AF, Hach M. Secretory expression and characterization of insulin in Pichia pastoris. Biotechnol Appl Biochem. 1999;29(1):79-86.

14. Liang S, Li C, Ye Y, Lin Y. Endogenous signal peptides efficiently mediate the secretion of recombinant proteins in Pichia pastoris. Biotechnol Lett. 2013;35(1):97-105.

15. Macauley-Patrick S, Fazenda ML, McNeil B, Harvey LM. Heterologous protein production using the Pichia pastoris expression system. Yeast. 2005;22(4):249-70.

16. Cereghino JL, Cregg JM. Heterologous protein expression in the methylotrophic yeast Pichia pastoris. FEMS Microbiol Rev. 2000;24(1):45-66.

17. Mellitzer A, Glieder A, Weis R, Reisinger C, Flicker K. Sensitive highthroughput screening for the detection of reducing sugars. Biotechnol J. 2012;7(1):155-62.

18. Weinhandl K, Winkler M, Glieder A, Camattari A. A novel multi-enzymatic high throughput assay for transaminase activity. Tetrahedron. 2012;68(37):7586-90.

19. Marx H, Mecklenbräuker A, Gasser B, Sauer M, Mattanovich D. Directed gene copy number amplification in Pichia pastoris by vector integration into the ribosomal DNA locus. FEMS Yeast Res. 2009:9(8):1260-70.

20. Nordén K, Agemark M, Danielson JÅ, Alexandersson E, Kjellbom P, Johanson $U$. Increasing gene dosage greatly enhances recombinant expression of aquaporins in Pichia pastoris. BMC Biotechnol. 2011;11(1):47.

21. Hohenblum H, Gasser B, Maurer M, Borth N, Mattanovich D. Effects of gene dosage, promoters, and substrates on unfolded protein stress of recombinant Pichia pastoris. Biotechnol Bioeng. 2004:85(4):367-75.

22. Zhao X, Xie W, Lin Y, Lin X, Zheng S, Han S. Combined strategies for improving the heterologous expression of an alkaline lipase from Acinetobacter radioresistens CMC-1 in Pichia pastoris Process Biochem 2013;48(9):1317-23.

23. Whyteside G, Alcocer MJ, Kumita JR, Dobson CM, Lazarou M, Pleass RJ, et al. Native-state stability determines the extent of degradation relative to secretion of protein variants from Pichia pastoris. PLoS One. 2011;6(7):e22692

24. Cudna RE, Dickson AJ. Endoplasmic reticulum signaling as a determinant of recombinant protein expression. Biotechnol Bioeng. 2003;81(1):56-65.

25. Damasceno LM, Huang C-J, Batt CA. Protein secretion in Pichia pastoris and advances in protein production. Appl Microbiol Biotechnol. 2012;93(1):31-9.

26. Guerfal M, Ryckaert S, Jacobs PP, Ameloot P, Van Craenenbroeck K, Derycke $R$, et al. Research The HAC1 gene from Pichia pastoris: characterization and effect of its overexpression on the production of secreted, surface displayed and membrane proteins. Microb Cell Fact. 2010;9:49.

27. Valkonen M, Penttilä M, Saloheimo M. Effects of inactivation and constitutive expression of the unfolded-protein response pathway on protein production in the yeast Saccharomyces cerevisiae. Appl Environ Microbiol. 2003;69(4):2065-72

28. Lin X-q, S-y H, Zhang N, Hu H, Zheng S-p, Ye Y-r, et al. Bleach boosting effect of xylanase A from Bacillus halodurans C-125 in ECF bleaching of wheat straw pulp. Enzym Microb Technol. 2013;52(2):91-8.

29. Kim M-D, Han K-C, Kang H-A, Rhee S-K, Seo J-H. Coexpression of BiP increased antithrombotic hirudin production in recombinant Saccharomyces cerevisiae. J Biotechnol. 2003;101(1):81-7.

30. Shusta EV, Raines RT, Plückthun A, Wittrup KD. Increasing the secretory capacity of Saccharomyces cerevisiae for production of single-chain antibody fragments. Nat Biotechnol. 1998;16(8):773-7.
31. Ruddock $L$ : Method for producing natively folded proteins in a prokaryotic host. In:: Google Patents; 2011.

32. Kincaid MM, Cooper AA. ERADicate ER stress or die trying. Antioxid Redox Signal. 2007;9(12):2373-87.

33. Haynes CM, Titus EA, Cooper AA. Degradation of misfolded proteins prevents ER-derived oxidative stress and cell death. Mol Cell. 2004;15(5):767-76.

34. Pfaffl MW. A new mathematical model for relative quantification in real-time RT-PCR. Nucleic Acids Res. 2001;29(9):e45.

35. Waterham HR, Digan ME, Koutz PJ, Lair SV, Cregg JM. Isolation of the Pichia pastoris glyceraldehyde-3-phosphate dehydrogenase gene and regulation and use of its promoter. Gene. 1997;186(1):37-44.

36. Zyla K, Koreleski J, Światkiewicz S, Wikiera A, Kujawski M, Piironen J, et al. Effects of phosphorolytic and cell wall-degrading enzymes on the performance of growing broilers fed wheat-based diets containing different calcium levels. Poult Sci. 2000;79(1):66-76.

37. Xiong AS, Yao QH, Peng RH, Han PL, Cheng ZM, Li Y. High level expression of a recombinant acid phytase gene in Pichia pastoris. J Appl Microbiol. 2005;98(2):418-28.

38. Abad S, Kitz K, Hörmann A, Schreiner U, Hartner FS, Glieder A: Real-time PCR-based determination of gene copy numbers in Pichia pastoris. Biotechnology journal 2010;5(4):413-420.

39. Hou J, Tyo KE, Liu Z, Petranovic D, Nielsen J. Metabolic engineering of recombinant protein secretion by Saccharomyces cerevisiae. FEMS Yeast Res. 2012;12(5):491-510.

40. Gasser B, Saloheimo M, Rinas U, Dragosits M, Rodríguez-Carmona E, Baumann $\mathrm{K}$, et al. Protein folding and conformational stress in microbial cells producing recombinant proteins: a host comparative overview. Microb Cell Factories. 2008;7(1):11.

41. Ahmad M, Hirz M, Pichler $H$, Schwab H. Protein expression in Pichia pastoris: recent achievements and perspectives for heterologous protein production. Appl Microbiol Biotechnol. 2014;98(12):5301-17.

42. Xiong A-S, Yao Q-H, Peng R-H, Zhang Z, Xu F, Liu J-G, et al. High level expression of a synthetic gene encoding Peniophora lycii phytase in methylotrophic yeast Pichia pastoris. Appl Microbiol Biotechnol. 2006;72(5):1039-47

43. Yang M, Johnson SC, Murthy PP. Enhancement of alkaline phytase production in Pichia pastoris: influence of gene dosage, sequence optimization and expression temperature. Protein Expr Purif. 2012:84(2):247-54.

44. Primm TP, Walker KW, Gilbert HF. Facilitated protein aggregation effects of calcium on the chaperone and anti-chaperone activity of protein disulfideisomerase. J Biol Chem. 1996:271(52):33664-9.

45. Robinson AS, Hines V, Wittrup KD. Protein disulfide isomerase overexpression increases secretion of foreign proteins in Saccharomyces cerevisiae. Nat Biotechnol. 1994;12(4):381-4.

46. Gasser B, Maurer M, Gach J, Kunert R, Mattanovich D. Engineering of Pichia pastoris for improved production of antibody fragments. Biotechnol Bioeng. 2006:94(2):353-61.

47. Inan M, Aryasomayajula D, Sinha J, Meagher MM. Enhancement of protein secretion in Pichia pastoris by overexpression of protein disulfide isomerase. Biotechnol Bioeng. 2006;93(4):771-8.

48. Gasser B, Sauer M, Maurer M, Stadlmayr G, Mattanovich D. Transcriptomics based identification of novel factors enhancing heterologous protein secretion in yeasts. Appl Environ Microbiol. 2007;73(20):6499-507.

49. Wentz AE, Shusta EV. A novel high-throughput screen reveals yeast genes that increase secretion of heterologous proteins. Appl Environ Microbiol. 2007;73(4):1189-98

50. Robinson AS, Bockhaus JA, Voegler AC, Wittrup KD. Reduction of BiP levels decreases heterologous protein secretion in Saccharomyces cerevisiae. J Biol Chem. 1996;271(17):10017-22

51. Lin X-q, Liang S-I, Han S-y, Zheng S-p, Ye Y-r, Lin Y. Quantitative iTRAQ LC-MS/MS proteomics reveals the cellular response to heterologous protein overexpression and the regulation of $\mathrm{HACl}$ in Pichia pastoris. J Proteome. 2013;91:58-72

52. Xu P, Robinson AS. Decreased secretion and unfolded protein response up-regulation are correlated with intracellular retention for single-chain antibody variants produced in yeast. Biotechnol Bioeng. 2009;104(1):20-9. 